\begin{tabular}{|c|c|}
\hline \multirow{3}{*}{ 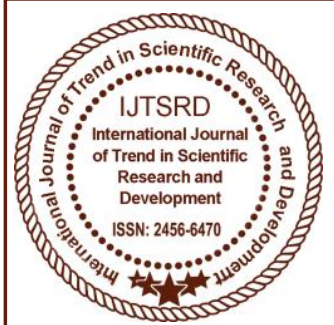 } & $\begin{array}{l}\text { International Journal of Trend in Scientific } \\
\text { Research and Development (IJTSRD) }\end{array}$ \\
\hline & UGC Approved International Open Access Journal \\
\hline & ISSN No: 2456 - 6470 | www.ijtsrd.com | Volume - 1 | Issue - 5 \\
\hline
\end{tabular}

\title{
To Compare the Effect of Proprioceptive Neuromuscular Facilitation and Static Stretching on Flexibility of Hamstring Muscle a Comparative Study
}

\author{
Tanu Kapila \\ DAV Institute of Physiotherapy \\ and Rehabilitation, \\ Jalandhar, Punjab
}

\author{
Dilpreet Kaur \\ DAV Institute of Physiotherapy \\ and Rehabilitation, \\ Jalandhar, Punjab
}

\author{
Jaspinder Kaur* \\ DAV Institute of Physiotherapy \\ and Rehabilitation, \\ Jalandhar, Punjab
}

\begin{abstract}
\section{Background:}

Flexibility is an important physiological component of physical fitness and reduced flexibility can cause inefficiency in the workplace and is also a risk factor for low back pain. Increasing hamstring flexibility was reported to be an effective method for increasing hamstring muscle performance.
\end{abstract}

\section{Objective:}

To compare the effects of modified hold-relax proprioceptive neuromuscular facilitation stretching technique and static stretching on flexibility of hamstring muscle.

\section{Materials and Methods:}

In this comparative study 60 subjects were selected by convenience sampling and research design was comparative and experiment in nature. Subjects were selected on the basis of inclusion criteria. Subjects were divided into two groups, group A and group B allocating alternate subjects to group A and group B, 30 in each group. Group A was treated with Proprioceptive Neuromuscular Facilitation with cryotherapy and Group B was treated with Static Stretching with cryotherapy. Baseline assessment was taken on pre stretch, post stretch and after 24 hours using Active Knee Extension test and Modified back saver sit and reach test.

\section{Results:}

Both the groups showed significant improvement in hamstring flexibility. $(\mathrm{p}<0.005)$. On comparing the pre stretch, post stretch and after 24 hours reading within the Group A and Group B, there was significant improvement in hamstring flexibility $(\mathrm{p}<0.05)$. But on comparing both the groups, there was no significant difference in hamstring muscle flexibility $(\mathrm{p}>0.05)$.

\section{Conclusion:}

Thus we concluded that the Proprioceptive Neuromuscular Facilitation Stretching Technique and Static Stretching both are effective to improve flexibility of hamstring muscle and clinically both the interventions are equally effective.

Keywords: Hamstring flexibility, Proprioceptive Neuromuscular Facilitation, Static stretching, Cryotherapy, Active Knee Extension test, Modified back saver sit and reach test.

\section{INTRODUCTION}

Muscular flexibility is an important aspect of normal human function. ${ }^{1}$ It is generally defined as range of motion around a joint or group of joints and reflects the ability of the muscle tendon to elongate. It has long been recognized as an important component of physical fitness and rehabilitation and is widely conjectured that benefits of good flexibility include 
reduction and prevention of injury risk and enhanced sports performance. ${ }^{1}$

Flexibility is a vital component of a physical conditioning program that allows the tissue to accommodate easily to stress, to dissipate shock impact and to improve efficiency of movement, thus minimizing or preventing injury. ${ }^{2}$ Adequate flexibility is an important characteristic of physical fitness. ${ }^{2}$ Limited flexibility has been shown to predispose a person to several musculoskeletal injury and significantly affect a person's level of function. ${ }^{3}$ The hamstrings play a crucial role in many daily activities. The hamstring muscles serve many purposes in the body such as walking, running, jumping and most importantly they serve as antagonists to the quadriceps in deceleration of knee extension. Tight hamstrings can lead to injury and hamstring strains are amongst the most common musculotendinous injuries of the lower extremities. ${ }^{4}$

Often the term flexibility is use to refer more specifically to the ability of musculotendinous unit to elongate as a body segment or when joint moves through a range of motion. Maintenance of flexibility is an essential component of any conditioning program in developing its mobility, improving athletic performance and preventing injuries. Good flexibility provides relaxation, eases muscle pain, helping quick recovery, reducing stress, keeps the body feel loose and agile ${ }^{5,6}$ as two joint muscle, the ability to produce effective force at the knee is influenced by the relative position of the other joint over which that muscle crosses to maintain proper balance and centre of gravity with shortening of hamstring muscle which makes it more complicated resulting in musculoskeletal problem of upper and lower back, hip, knee and foot. The hamstring balance out the quadriceps muscles onthe front of thigh and are necessary for walking and most other physical activities. Weak or excessively tight hamstrings can lead to altered biomechanics and can lead to knee or back injuries. Because the hamstrings are such a long muscle group and cross over both hip and knee joint, they are more prone to injury and tightness ${ }^{6,7}$

PNF Stretching technique was originally developed by Knott and Voss and Kabat, during 1940's and 1954 's as a means to treat neuromuscular conditions including polio and multiple sclerosis. ${ }^{8}$ The terms 'contract relax', 'hold relax' and 'contract relax agonist contraction' are most commonly referred in
PNF stretching literature. Usually contract relax and hold relax represents a passive placement of target muscle. The target muscle is then passively moved into a greater position of stretch. ${ }^{9}$ Contract relax agonist contraction often refers to technique that is similar to contract relax and hold relax except that following uses the static contraction of the target muscle, a shortening contraction of opposite muscle is utilised to place target muscle into a new position of stretch, which culminates in addition to passive stretch. ${ }^{10}$

Static stretching has been defined as a stationary stretch, held for a period of time, which specified joints are locked in a position that places the muscle and connective tissue at their greatest possible length. ${ }^{11}$ It is a form of passive stretching in which an external force exerts upon the limb to move it into the new position. ${ }^{12}$ This is in contrast to active stretching .Passive stretching resistance is normally achieved through the force of gravity on the limb or an the body weighing down on it. ${ }^{13}$

The principle methods of cold modalities to improve efficacy of stretching are by reducing muscle pain and muscle guarding. ${ }^{4}$ Cryotherapy decreases nervous conduction velocity and consequently, pain and muscle spindle discharge. Applying ice prior to stretching optimizes improvements in flexibility, since the muscle reflex response and pain are considered the main barriers to stretching maneuvers. ${ }^{3}$

The hamstring muscle are commonly linked with movement dysfunction at the lumbar spine, pelvis and lower limbs, and have been coupled with low back pain and gait abnormality (Mok et al., 2004; Orchard et al.,2004; vleeming and stoeckart, 2007).Considering the importance of hamstring flexibility in general and athletic population, maintaining the flexibility of hamstring muscle is of utmost importance for health care professionals and to achieve this goal one needs to know effective and efficient technique to gain hamstring flexibility. ${ }^{7}$

In the past, much of the literature has focused on the relationship between hamstring flexibility and injury and the most effective hamstring stretching method. Sullivan et al reported that no significant difference existed between static and proprioceptive neuromuscular facilitation hamstring stretching. This conflict with most studies that report the superiority of PNF stretching compared with static stretching. ${ }^{14}$ 


\section{METHOD}

A total of 60 subjects with hamstring muscle tightness were included in this study. Subjects under the inclusion and exclusion criteria were conveniently selected in the study and procedure was explained in detail and there after written consent form was taken from all the subjects. After that, assessment and evaluation of subject was done on first day. Individuals were assessed by active knee extension test and modified saver back sit and reach test (Pre treatment, immediately after stretching, after 24 hours ).Minimum 60 subjects were selected for the study and were divided into 2 groups -group A and group B with random allocation method, alternate subject in each group.

\section{Procedure}

\section{Interventions of Group A}

Baseline assessments were taken using Active Knee Extension test and Modified back saver sit and reach test followed by:

Cryotherapy for 10 minutes followed by 3 stretching sessions.

PNF with 30 seconds of stretch with hold of 10 seconds in which 10 seconds of isometric contraction of hamstring muscle followed by 10 seconds of relaxation in between the stretching session.

\section{Interventions of Group B}

Baseline assessments were taken using Active Knee Extension test and Modified back saver sit and reach test followed by:

Cryotherapy for 10 minutes.

$>$ Static stretching passively with 30 seconds of stretch with hold 10 seconds in between the stretching session.

The Active Knee Extension Test for Measuring Hamstring Tightness

Position of Patient

The subject was asked to lie in supine position, the testing was done on the both extremity.

The left lower extremity and the pelvis were strapped down the table to stable the pelvis and control any accessory movements.

The hip and knee of the extremity being tested was placed into 90 degree Flexion.

\section{GONIOMETER ALIGNMENT}

Landmarks used to measure hip and knee range of motion were greater trochanter, lateral condyle of femur and the lateral malleolus which were marked by a marker.

INSTRUCTIONS: The subject was then asked to extend the lower extremity as far as possible until a mild stretch sensation was felt. A full circle goniometer was then used to measure the angle of knee flexion .Previous research using radiography has established a good validity of goniometric measurements. ${ }^{16}$ Three repetitions were performed and an average of the three was taken as the final reading for knee extension range of motion (hamstring tightness).

\section{Modified Back Saver Sit and Reach Test}

The procedure for the BSSR was similar to those described in the prudential FITNESSGRAM test manual (Cooper Institute for Aerobics Research).Subjects position will be sitting with knee extended. The test will be administered using a SR box. The participant sat opposite to SR box and fully extended one leg so that the sole of foot rest fully against that box and the other leg has to be bend so that the sole of other foot will rest against floor and 7$10 \mathrm{~cm}$ to the side of straight knee. With the extended leg as straight as possible, hands on top of each other (tips of middle fingers parallel and even), palms facing down, and the participant slowly trying to reach forward slide the hands along the box scale as far as possible. Three repetitions were performed and an average of the three was taken as the final reading.

\section{STRETCHING PROCEDURES}

\section{For Passive Stretch (Static Stretching):-}

The subjects were asked to concentrate on relaxing the muscles of the leg and thigh as much as possible while the examiner passively flexed the hip joint to the point of muscular restriction.

Knee extension was gradually increased manually for 30 s; this was given thrice with rest period of $10 \mathrm{~s}$ during the stretch.

For Hold Relax PNF Stretch:- 
The subject was comfortably positioned in a supine lying position on a plinth with the hip flexed at 90 degrees of flexion, and examiner then stretched the Hamstrings passively until the subject felt a mild stretch sensation and that position was held for 10 seconds. The subjects were asked to perform maximal isometric contractions of the Hamstrings for 10 seconds against the resistance of the therapist. After the contraction, the subjects were instructed to relax for 10 seconds; this was given thrice with rest period of 10 s during the stretch.

\section{STATISTICAL ANALYSIS}

Unpaired t-test was used to compare the scores of baseline assessments between the two groups to find out whether the two groups were comparable or not and on comparing the data there was no any significant difference between two groups. So groups were comparable $(p>0.05)$. Statistical test used for the analysis of scores of Active Knee Extension test and Modified saver back sit and reach test by using Repeated ANOVA test and Tukey's method within the group and between the groups respectively.

\section{INTERPRETATION:}

Table 1.Comparison of Age between Group A and Group B

\begin{tabular}{|c|c|c|}
\hline \multirow{2}{*}{ Unpaired T Test } & \multicolumn{2}{|c|}{ Comparison } \\
\cline { 2 - 3 } & \multicolumn{2}{|c|}{ AGE } \\
\cline { 2 - 3 } & Group A & Group B \\
\hline Mean & 21.80 & 22.07 \\
\hline S.D. & 1.270 & 1.946 \\
\hline Unpaired T Test & \multicolumn{2}{|c|}{0.628} \\
\hline P value & \multicolumn{2}{|c|}{$>0.05$} \\
\hline Result & \multicolumn{2}{|c|}{ Not-Significant } \\
\hline
\end{tabular}

GRAPH -1

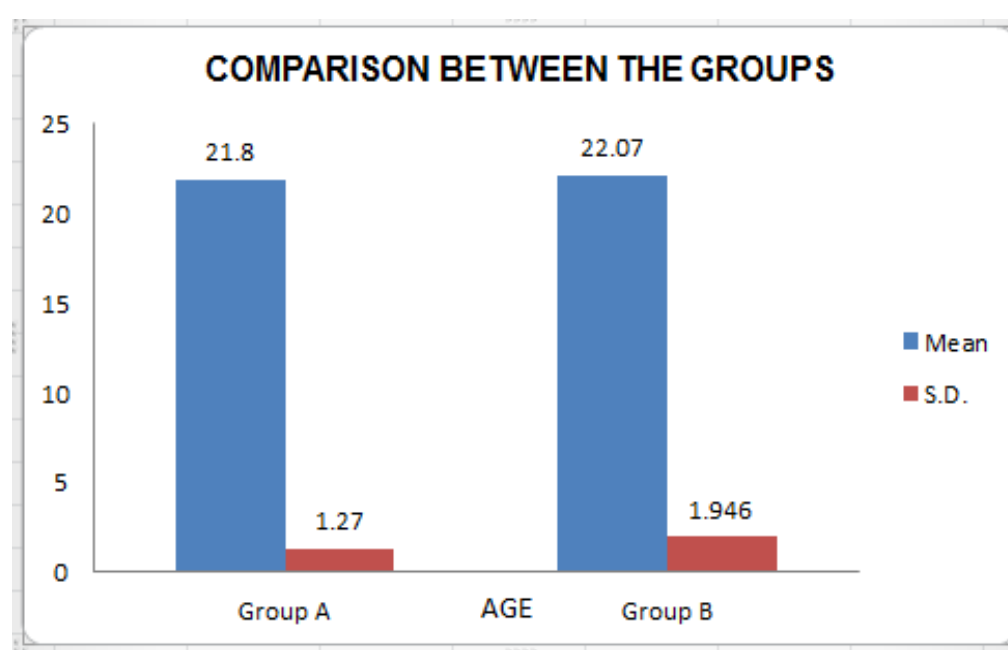

Table 2: Comparison of Gender between Group A and Group B

\begin{tabular}{|c|c|c|}
\hline \multirow{2}{*}{ Frequency (\%) } & \multicolumn{2}{|c|}{ Gender } \\
\cline { 2 - 3 } & Group A & Group B \\
\hline Male\% & 43.3 & 46.7 \\
\hline Female\% & 56.7 & 53.3 \\
\hline Male & 13.00 & 14.00 \\
\hline Female & 17.00 & 16.00 \\
\hline
\end{tabular}

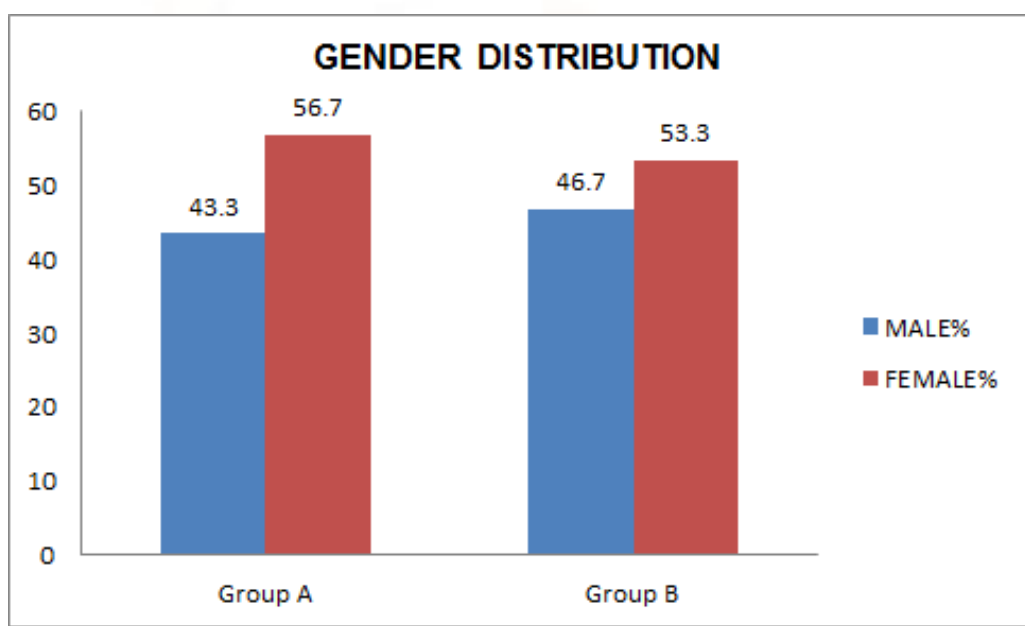

GRAPH-2 
Table 3: Comparison of Active Knee Extension test within Group A

\begin{tabular}{|c|c|c|c|}
\hline \multirow{2}{*}{ Repeated ANOVA } & \multicolumn{3}{|c|}{ Group A } \\
\hline & PRE & POST TEST & After 24 HOURS \\
\cline { 2 - 4 } & & 57.27 & 55.43 \\
\hline Mean & 53.03 & 8.749 & 8.553 \\
\hline S.D. & 8.876 & 82.05 \\
\hline F Test & \multicolumn{3}{|c|}{$<0.005$} \\
\hline P value & \multicolumn{3}{|c|}{ Significant } \\
\hline Result & \multicolumn{3}{|c|}{} \\
\hline
\end{tabular}

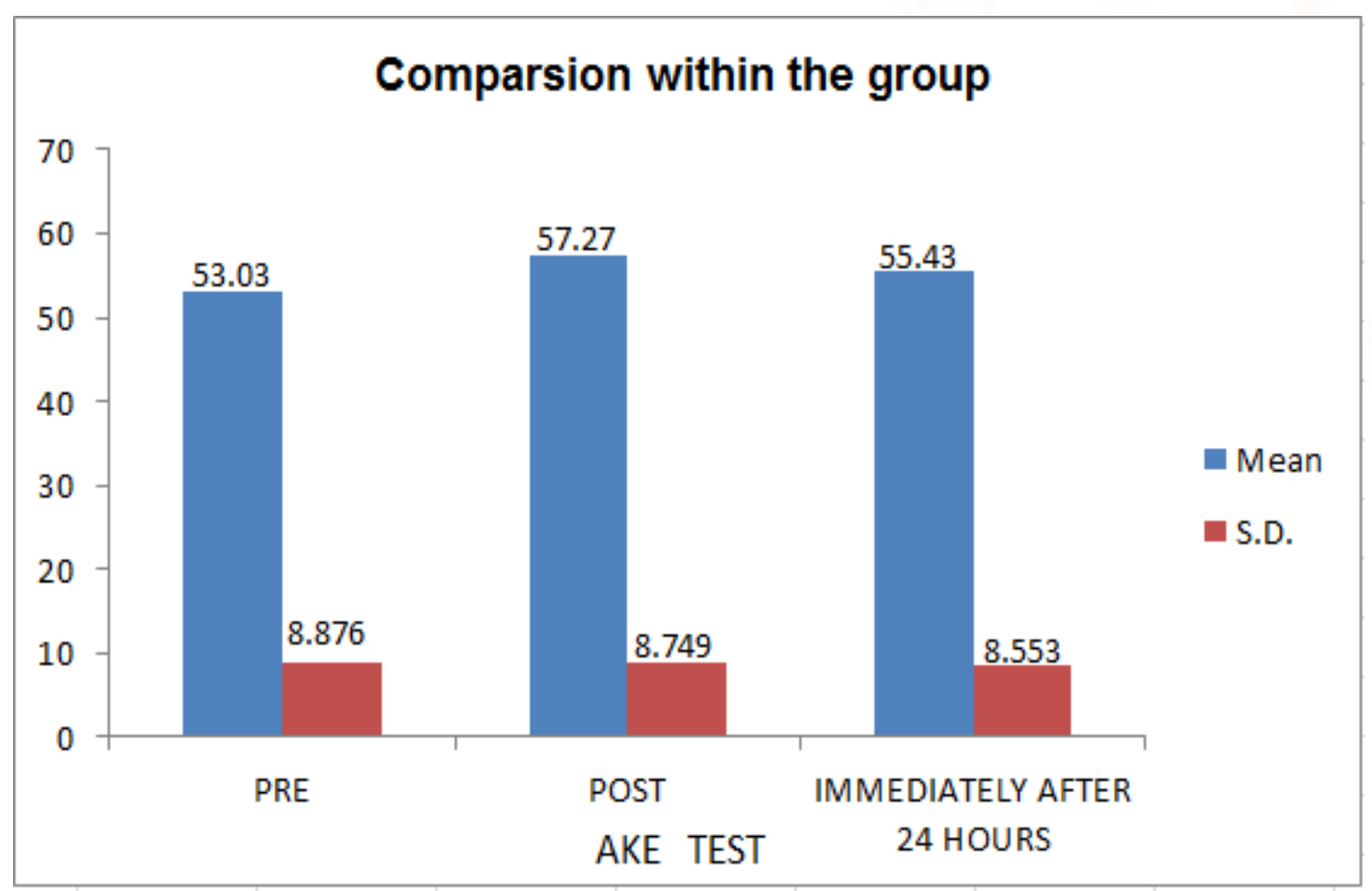

GRAPH -3

Table 4: Comparison of Modified back saver sit and reach test within Group A

\begin{tabular}{|c|c|c|c|}
\hline \multirow{2}{*}{ Repeated ANOVA } & \multicolumn{3}{|c|}{ Group A } \\
\cline { 2 - 4 } & MODIFIED BACK SA VER SIT AND REACH TEST \\
\cline { 2 - 4 } & PRE & POST & After 24 HOURS \\
\hline Mean & 7.10 & 7.88 & 7.51 \\
\hline S.D. & 2.429 & 2.399 & 2.405 \\
\hline F Test & \multicolumn{3}{|c|}{156.10} \\
\hline P value & \multicolumn{3}{|c|}{ Significant } \\
\hline 00Result & \multicolumn{3}{|c|}{ Signe } \\
\hline
\end{tabular}




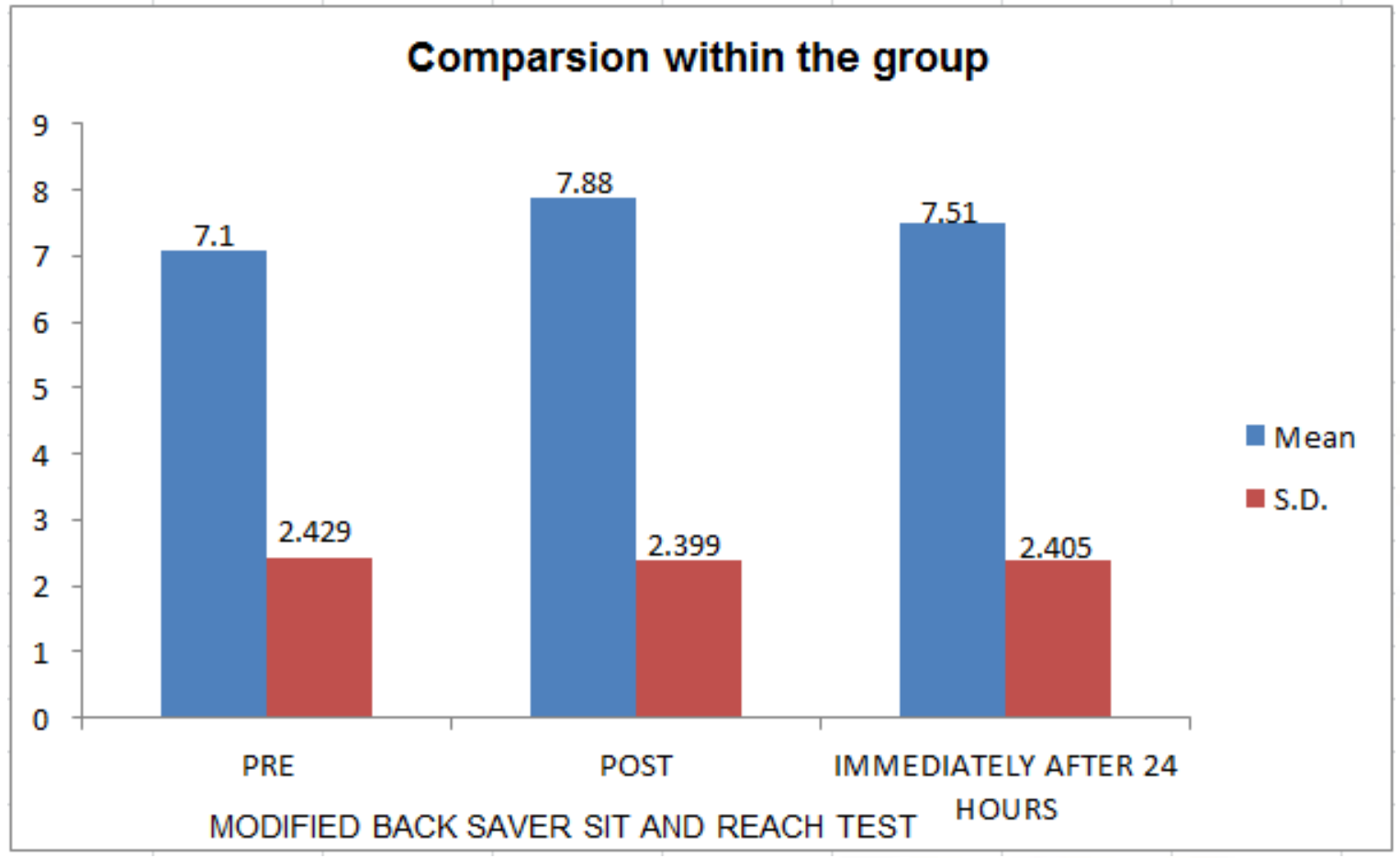

GRAPH - 4

Table 5: Comparison of Active knee extension test within Group B

\begin{tabular}{|c|c|c|c|}
\hline \multirow{2}{*}{ Repeated ANOVA } & \multicolumn{3}{|c|}{ GroupB } \\
\hline & PRE & POST & After 24 HOURS \\
\cline { 2 - 4 } & 50.23 & 57.73 & 55.60 \\
\hline Mean & 8.846 & 8.578 & 8.476 \\
\hline S.D. & \multicolumn{3}{|c|}{316.97} \\
\hline F Test & \multicolumn{3}{|c|}{ Significant } \\
\hline P value & \multicolumn{3}{|c|}{ Sign TES } \\
\hline Result & \multicolumn{3}{|c|}{} \\
\hline
\end{tabular}

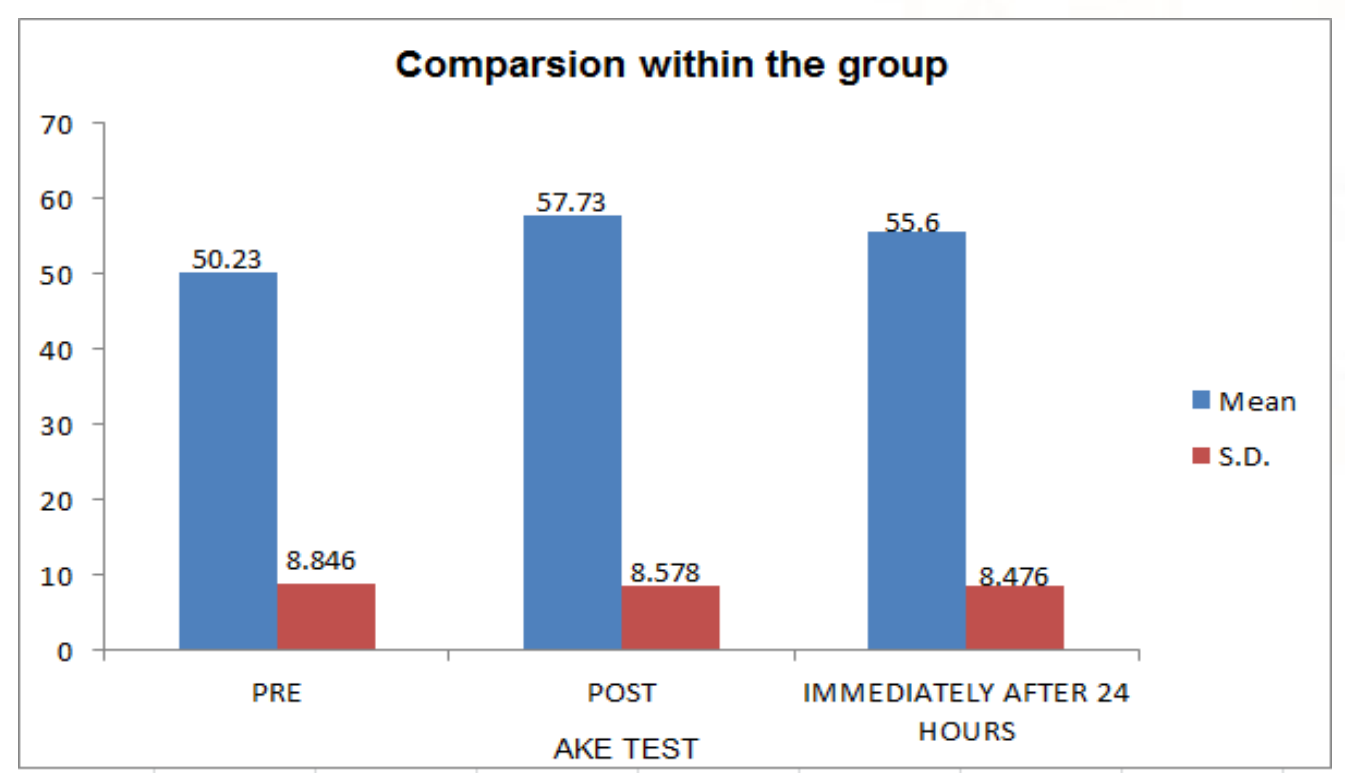

GRAPH- 5 
International Journal of Trend in Scientific Research and Development (IJTSRD) ISSN: 2456-6470

Table 6: Comparison of Modified back saver sit and reach test within Group B

\begin{tabular}{|c|c|c|c|}
\hline \multirow{2}{*}{ Repeated ANOVA } & \multicolumn{3}{|c|}{ Group-B } \\
\hline & \multicolumn{3}{|c|}{ MODIFIED BACK SA VER SIT AND REACH } \\
TEST \\
\cline { 2 - 4 } & PRE & POST & After 24 HOURS \\
\hline Mean & 6.49 & 7.34 & 7.13 \\
\hline S.D. & 3.101 & 3.024 & 2.949 \\
\hline F Test & \multicolumn{3}{|c|}{91.73} \\
\hline P value & \multicolumn{3}{|c|}{ Significant } \\
\hline Result & \multicolumn{3}{|c|}{} \\
\hline
\end{tabular}

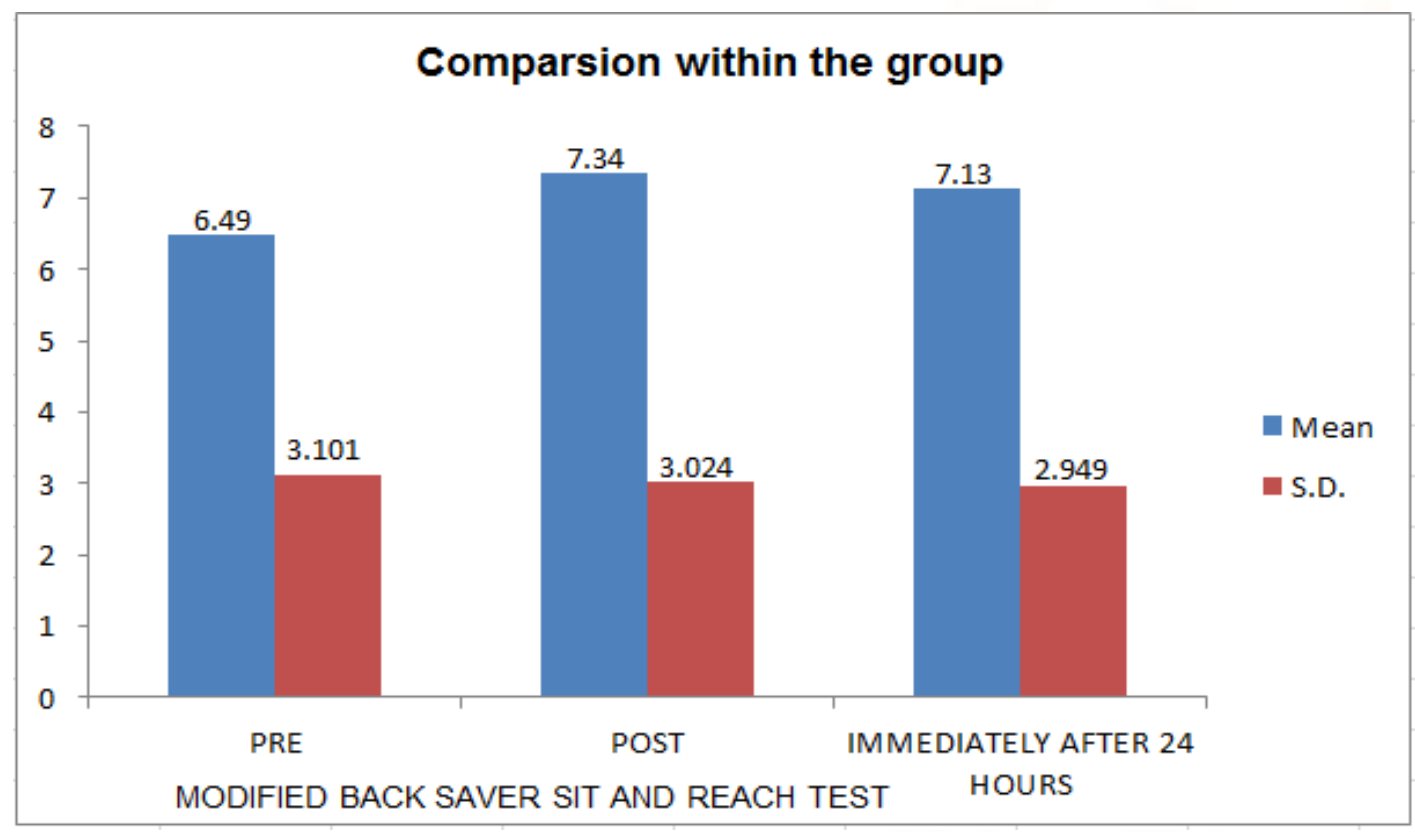

GRAPH- 6

Table 7: Comparison of Active Knee Extension test between the Group A \& Group B

\begin{tabular}{|c|c|c|c|c|c|c|}
\hline \multirow{2}{*}{ Unpaired T Test } & \multicolumn{9}{c|}{ AKE TEST } \\
\cline { 2 - 7 } & \multicolumn{2}{|c|}{ PRE } & \multicolumn{2}{c|}{ POST } & \multicolumn{2}{c|}{ After 24 HOURS } \\
\cline { 2 - 7 } & $\begin{array}{c}\text { Group } \\
\text { A }\end{array}$ & $\begin{array}{c}\text { Group } \\
\text { B }\end{array}$ & $\begin{array}{c}\text { Group } \\
\text { A }\end{array}$ & $\begin{array}{c}\text { Group } \\
\text { B }\end{array}$ & $\begin{array}{c}\text { Group } \\
\text { A }\end{array}$ & $\begin{array}{c}\text { Group } \\
\text { B }\end{array}$ \\
\hline Mean & 53.03 & 50.23 & 57.27 & 57.73 & 55.43 & 55.60 \\
\hline S.D. & 8.876 & 8.846 & 8.749 & 8.578 & 8.553 & 8.476 \\
\hline Unpaired T Test & \multicolumn{2}{|c|}{1.224} & 0.209 & & 0.076 \\
\hline P value & \multicolumn{2}{|c|}{$>0.05$} & \multicolumn{2}{c|}{$>0.05$} & \multicolumn{2}{c|}{$>0.05$} \\
\hline Result & \multicolumn{3}{|c|}{ Not-Significant } & Not-Significant & Not-Significant \\
\hline
\end{tabular}




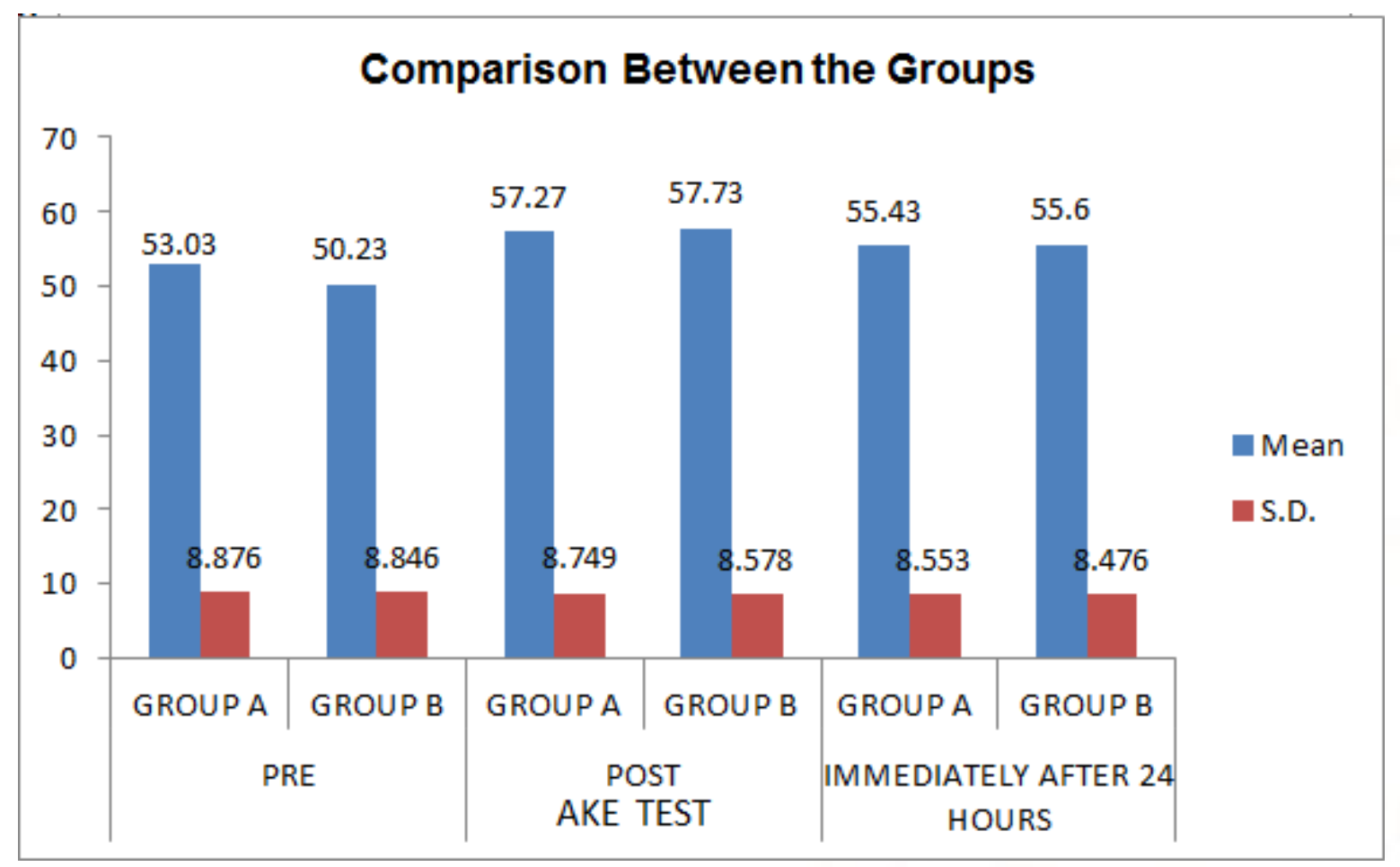

GRAPH -7

Table 8: Comparison of Modified back saver sit and reach test between the Group A\& Group B

\begin{tabular}{|c|c|c|c|c|c|c|}
\hline \multirow{2}{*}{ Unpaired T Test } & \multicolumn{3}{|c|}{ MODIFIED BACK SA VER SIT AND REACH TEST } \\
\cline { 2 - 7 } & \multicolumn{2}{|c|}{ PRE } & \multicolumn{2}{c|}{ POST } & \multicolumn{2}{c|}{ After 24 HOURS } \\
\cline { 2 - 7 } & $\begin{array}{c}\text { Group } \\
\text { A }\end{array}$ & $\begin{array}{c}\text { Group } \\
\text { B }\end{array}$ & $\begin{array}{c}\text { Group } \\
\text { A }\end{array}$ & $\begin{array}{c}\text { Group } \\
\text { B }\end{array}$ & $\begin{array}{c}\text { Group } \\
\text { A }\end{array}$ & $\begin{array}{c}\text { Group } \\
\text { B }\end{array}$ \\
\hline Mean & 7.10 & 6.49 & 7.88 & 7.34 & 7.51 & 7.13 \\
\hline S.D. & 2.429 & 3.101 & 2.399 & 3.024 & 2.405 & 2.949 \\
\hline Unpaired T Test & \multicolumn{2}{|c|}{0.848} & 0.766 & \multicolumn{2}{c|}{0.552} \\
\hline P value & \multicolumn{2}{|c|}{$>0.05$} & $>0.05$ & \multicolumn{2}{c|}{$>0.05$} \\
\hline Result & \multicolumn{2}{|c|}{ Not-Significant } & Not-Significant & \multicolumn{2}{c|}{ Not-Significant } \\
\hline
\end{tabular}




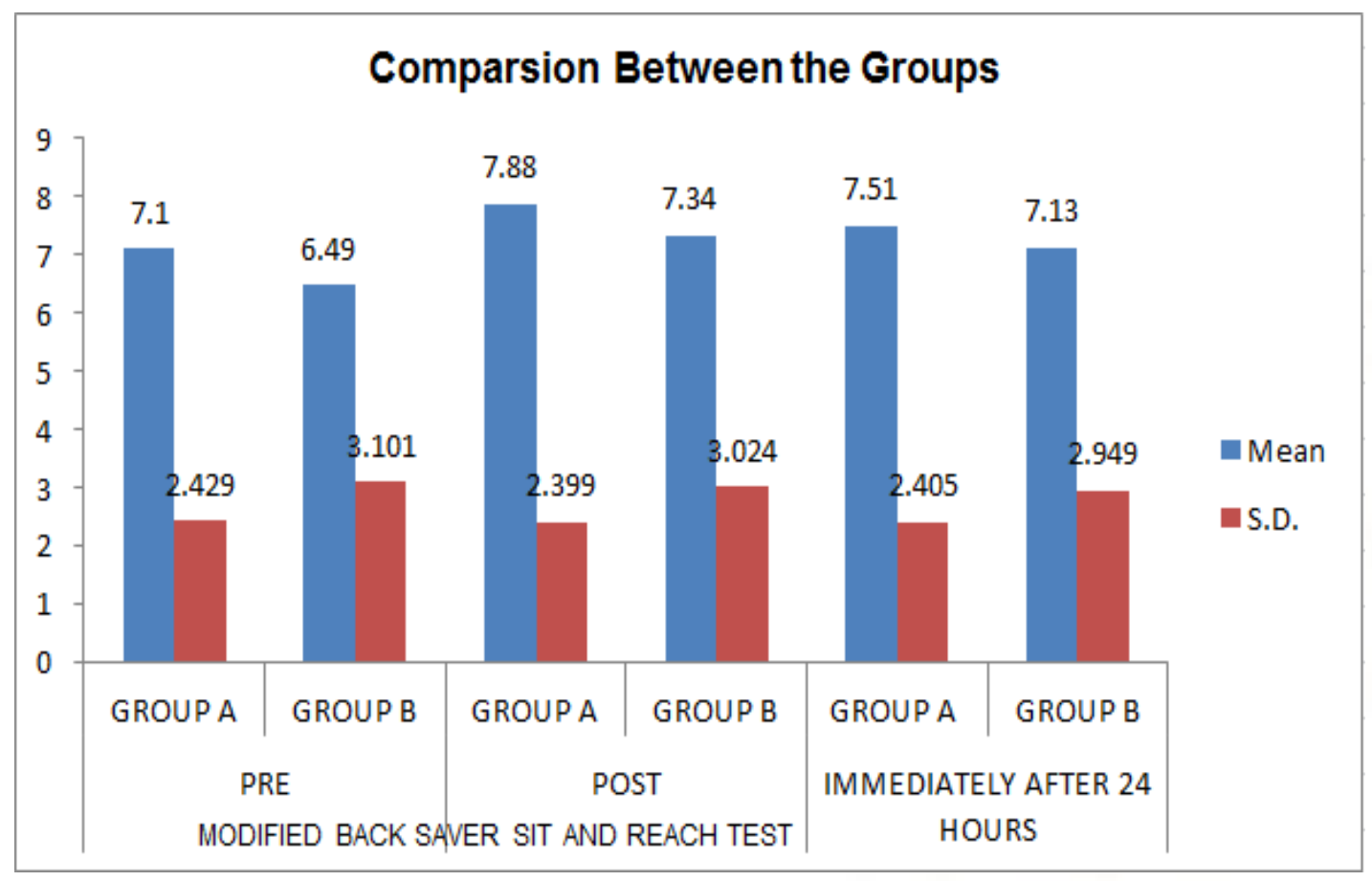

GRAPH -8

\section{RESULTS}

Sixty subjects were selected for the study. After selecting, the subjects were randomly divided into two equal groups, group A and group B. Thirty subjects were taken in each group. Group A was given Proprioceptive Neuromuscular Stretching with Cryotherapy and Group B was given Static Stretching with Cryotherapy. Subjects were assessed by Active knee extension test and Modified back saver sit and reach test (Pre stretch, Post stretch and after 24 hours).

> Comparison of each component on Pre stretch, Post stretch and immediately after 24 hours for both the groups was done by using unpaired t-test with assuming no normality and its p-value was > 0.05 then the results were not significant and if p-value was $<0.05$ then result were significant.

Table 1. Shows Comparison of Age between the groups that there was no significant difference between the Group $\mathrm{A}$ and $\mathrm{B}$ related to age $(\mathrm{P}>0.05)$ at the start of treatment. The mean age of Group A was $21.80 \pm 1.270$. The mean age of Group B was $22.07 \pm 1.946$. So, the Groups were comparable.

Table 2. Shows Frequency of males and females between the Group A and Group B. The number of males and females in group A was 13 males and 17 females. The number of males and females in group B was 14 males and 16 females.
Table 3. ShowsComparison of scores of AKE within group A (pre, post and after 24 hours of intervention) There was statistically significant improvement in flexibility of hamstring muscle $(p<0.005)$ during Proprioceptive Neuromuscular Facilitation Stretching technique by using active knee extension test.

Table 4. ShowsComparison of scores of Modified back saver sit and reach test within group A (pre, post and after 24 hours of intervention). There was statistically significant improvement in flexibility of hamstring muscle $(p<0.005)$ with Proprioceptive Neuromuscular Facilitation stretching technique.

$>$ Table 5. Shows Comparison of scores of AKE within group B (pre, post and after 24 hours of intervention).There was statistically significant improvement in flexibility of hamstring muscle $(\mathrm{p}<0.005)$ with Static Stretching technique

$>$ Table 6.ShowsComparison of scores of Modified back saver sit and reach test within group B (pre,post and after 24 hours of intervention). There was statistically significant improvement in flexibility of hamstring muscle $(\mathrm{p}<0.005)$ with Static Stretching technique.

Table 7. Shows Comparison of scores of AKE test between group A and group B(pre, post and after 24 hours of intervention). Unpaired t-test was appliedto compare the AKE between group $\mathrm{A}$ and 
group B on Pre stretch, Post stretch and after 24 hours. There was no statistically significant difference in hamstring flexibility in between both the groups $(\mathrm{P}>0.05)$.

Table 8. Shows the Comparison of scores of Modified back saver sit and reach test between group A and group B(pre, post and after 24 hours of intervention). Unpaired t-test was applied to compare the scores. There was no statistically significant difference in hamstring flexibility in between both the groups $(\mathrm{P}>0.05)$.

Thus the finding of our present study supports the $\mathrm{H}_{0}$ hypothesis. There is no significant difference between effects of Proprioceptive Neuromuscular Facilitation Stretching and Static Stretching on flexibility of hamstring muscle.

\section{DISCUSSION}

Flexibility is an important physiological component of physical fitness and reduced flexibility can cause inefficiency in the workplace and is also a risk factor for low back pain. Increasing hamstring flexibility was reported to be an effective method for increasing hamstring muscle performance. ${ }^{16}$ This study was designed to compare the effects of modified holdrelax proprioceptive neuromuscular facilitation stretching technique and static stretching on flexibility of hamstring muscle.

Modified hold-relax Proprioceptive Neuromuscular Facilitation Stretching improves flexibility through relaxation of the contractile component of the muscles, while static stretching causes an increase in elasticity of the non-contractile viscoelastic component ${ }^{15}$.Thus, the study demonstrated that both of these mechanisms play equal roles in improving the flexibility of the muscles.

The finding of study concurs with other previous studies that have reported similar results. Feland et al. had studied that contract-relax and static stretching similar benefits in improving flexibility ${ }^{17}$. Similarly, Gribble et al. found that static and hold-relax stretching were equally effective in improving hamstring range of motion ${ }^{15}$.

Recently Lim et al. had studied similar effects of static and PNF stretching on hamstring muscle extensibility $^{18}$.

A possible mechanism for the improvement of hamstring range of motion relies on the effects of autogenic inhibition. Autogenic inhibition is contingent on the function of the Golgi tendon organs, which not only detect changes in length but also changes in tension. Tension is produced in the antagonists with both static and PNF hamstring stretching techniques. Therefore, the presence of autogenic inhibition would not be affected if the measurement technique was an active or passive stretch or if the training method was a static or holdrelax stretch ${ }^{15}$.

Another possible mechanism for the increase in range of motion is augmentation of stretch tolerance. This is supported by Halbertsma et al., who reported an increase in hamstring flexibility in their study ${ }^{6}$. Sharma et al. reported stretching along with warming up is an effective way to improve hamstring flexibility $^{20}$. Moreover, their participants reported an increase in pain tolerance at the end of study. They attributed the gains in flexibility to an increase in stretch tolerance.

The results also suggest that a single session stretching does not deform tissues enough to produce a permanent change (i.e., a plastic deformation in the musculotendinous unit). Therefore, the temporary improvement in hamstring flexibility may be attributed tochanges in the elastic region caused by a single session of stretching ${ }^{19}$.

\section{CONCLUSION}

Thus present study concluded that the Proprioceptive Neuromuscular Facilitation Stretching technique and Static Stretching both are effective to improve flexibility of hamstring muscle and clinically both the interventions are equally effective.

\section{STUDY LIMITATION}

> Sample size was small.

$>$ Sample included only healthy young individuals and the result of this investigation should not be generalized to person outside the sample population.

$>$ The effect of the study was temporary, so prolonged stretching session can be carried out to see the effect of stretching on hamstring muscle.

$>$ The point of muscular restriction used for stretching was determined by the subject indicating point of resistance, but no pain and clinical soft tissue stretch and feel detected by therapist. 
International Journal of Trend in Scientific Research and Development (IJTSRD) ISSN: 2456-6470

\section{RECOMMENDATION}

$>$ We believe that further research with more participants and longer follow up periods could help to assess the long term benefits.

$>$ The duration of stretching in both groups can be alter to check the effectiveness of treatment.

$>$ Other outcome measures can be added to see the effect on flexibility of hamstring muscle.

$>$ Along with stretching to maintain the flexibility of hamstrings the subjects can be advised home stretching program.

\section{REFERENCES}

1) Chi-Hsiu Chen, Trevor C Chen et al.2009.'Effect of 8 week static stretch and PNF training on the Angle-Torque Relationship.' .Journal of Medical and bioengineering.vol2 nine,no.4pp 196-201.

2) Brodowicz GR, Welsh R, Wallis J. Comparison of stretching with ice, stretching with heat, or stretching alone on hamstring flexibility. Journal of athletic training. 1996 Oct;31(4):324.

3) Brasileiro JS, Faria AF, Queiroz LL. Influence of local cooling and warming on the flexibility of the hamstring muscles. Brazilian Journal of Physical Therapy. 2007 Feb;11(1):57-61.

4) kumarBoddeti R, Rao VT, Babu VS, Raj AO. A COMPARATIVE STUDY ON THE EFFECTS OF SUPERFICIAL HEATING AND COOLING APPLICATION OVER THE HAMSTRING PRIOR TO STRETCHING IN NORMAL INDIVIDUALS.

5) Wiemann K, Hahn K. Influences of strength, stretching and circulatory exercises on flexibility parameters of the human hamstrings. International journal of sports medicine. 1997 Jul;18(05):340-6.

6) Halbertsma JP, Goeken LN. Stretching exercises: effect on passive extensibility and stiffness in short hamstrings of healthy subjects. Archives of physical medicine and rehabilitation. 1994 Sep 1;75(9):976-81.

7) Nagarwal AK, Zutshi K, Ram CS, Zafar R, Hamdard J. Improvement of hamstring flexibility: A Comparison between two PNF stretching techniques. International journal of sports science and engineering. 2010;4(1):25-33.

8) Surburg PR, Schrader JW. Proprioceptive neuromuscular facilitation techniques in sports medicine: a reassessment. Journal of athletic training. 1997 Jan;32(1):34.

9) Ferber R, Osternig LR, Gravelle DC. Effect of PNF stretch techniques on knee flexor muscle
EMG activity in older adults. Journal of electromyography and kinesiology. 2002 Oct 31;12(5):391-7

10) Hanten WP, Chandler SD. Effects of myofascial release leg pull and sagittal plane isometric contract-relax techniques on passive straight-leg raise angle. Journal of Orthopaedic\& Sports Physical Therapy. 1994 Sep;20(3):138-44.

11) Zhu Q, Gu R, Yang X, Lin Y, Gao Z, Tanaka Y. Adolescent lumbar disc herniation and hamstring tightness: review of 16 cases. Spine. 2006 Jul 15;31(16):1810-4.

12) Kanlayanaphotporn $\quad R, \quad J a n w a n t a n a k u l \quad P$. Comparison of skin surface temperature during the application of various cryotherapy modalities. Archives of physical medicine and rehabilitation. 2005 Jul 31;86(7):1411-5.

13) Wang W. The Effects of static stretching versus dynamic stretching on lower extremity joint range of motion, static balance, and dynamic balance.

14) Worrell TW, Smith TL, Winegardner J. Effect of hamstring stretching on hamstring muscle performance. Journal of Orthopaedic\& Sports Physical Therapy. 1994 Sep;20(3):154-9..

15) Gribble PA, Guskiewicz KM, Prentice WE, Shields EW. Effects of static and hold-relax stretching on hamstring range of motion using the FlexAbility LE1000. Journal of Sport Rehabilitation. 1999 Aug;8(3):195-208.

16) Worrell TW, Smith TL, Winegardner J. Effect of hamstring stretching on hamstring muscle performance. Journal of Orthopaedic\& Sports Physical Therapy. 1994 Sep;20(3):154-9.

17) Feland JB, Myrer JW, Merril RM: Acute changes in hamstring flexibility: PNF versus static stretch in senior athletes. PhysTher Sport, 2001, 2: 186193

18) Lim KI, Nam HC, Jung KS. Effects on hamstring muscle extensibility, muscle activity, and balance of different stretching techniques. Journal of physical therapy science. 2014;26(2):209-13

19) Spernoga SG, Uhl TL, Arnold BL, Gansneder BM. Duration of maintained hamstring flexibility after a one-time, modified hold-relax stretching protocol. Journal of athletic training. 2001 Jan $1 ; 36(1): 44$.

20)

Sharma J, White C, Senjyu H. A Description of Single Case DesignAs an Example to Evaluate the Effect of Warm-up and Stretching on Hamstring Flexibility in a Clinical Setting. Journal of Physical Therapy Science. 2004;16(1):21-6. 